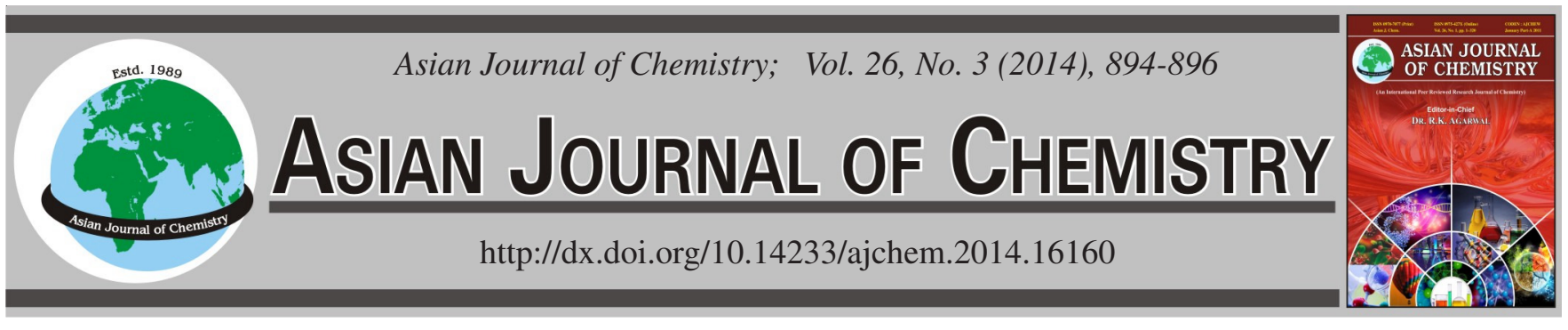

\title{
New Constituent from Fruits of Lycium chinense Miller
}

\author{
Ill-Min Chung, Ye-Seul Yang and Ateeque Ahmad*
}

Department of Applied Bioscience, Konkuk University, Seoul 143-701, Republic of Korea

*Corresponding author: E-mail: ateeque97@gmail.com

One new compound $\alpha$-D-glucopyranosyl-( $\left.2 \rightarrow 1^{\prime}\right)$ - $\alpha$-L-arabinopyranosyl-(2' $\rightarrow 1$ ")- $\alpha$-L-arabinopyranosyl-(2" $\left.\rightarrow 11^{\prime \prime}\right)-\alpha$-L-arabinopyranoside (1) was isolated and identified from the fruits of Lycium chinense. The chemical structure of new compound was elucidated by 1D and 2D NMR spectroscopic techniques (COSY, HMBC and HSQC) aided by FABMS and IR spectra and chemical reactions.

Keywords: Lycium chinense, Solanaceae, Fruits, New constituent.

\section{INTRODUCTION}

Lycium chinense Miller fruits (Fructus Lycii) known as "Gou-Qi-Zi" in Chinese, have long history of application as a valuable tonic and health food supplement for improving vision and maintaining good health. It is reputed to have the properties of nourishing the blood, enriching the yin, tonifying the kidney and liver, moistening the lungs ${ }^{1,2}$. Fruits of L. chinense (Solanaceae), distributed in northeast Asia, specially China, Japan, Korea and Taiwan, have been widely used as a tonic in traditional medicine. Potentially isolated constituents were reported to exhibit hypotensive, hypoglycemic and antipyretic activities ${ }^{3,4}$. Several compounds like cerebrosides and lyciumamide in this plant are known to display various bioactivities ${ }^{5,6}$. Potentially hepatoprotective glycolipid constituents and determination of betain in L. chinense fruits have been reported ${ }^{7,8}$. Antimicrobial compounds have also been reported from $L$. chinense roots ${ }^{9}$. Specific $\alpha$-galactosidase inhibitors, $\mathrm{N}$-methylcalystegines structure/activity relationship of calystegines from $L$. chinense have been reported ${ }^{10}$. The plant is reported to possess antibacterial, anticancer and antioxidant properties ${ }^{9,11,12}$. Antihepatotoxic activity and chemical constitutents from $L$. chinense fruits have been reported ${ }^{5,13}$.

Several compounds like cyclic peptides, acyclic diterpene glycosides and other compounds from $L$. chinense ${ }^{14}$, glycoconjugates from Lycium barbarum have been reported ${ }^{15}$. Variation in fruit sugar composition of L. barbarum and L. chinense of different regions and varieties were also reported ${ }^{16}$. Evaluation of antioxidant and other activities of compounds from $L$. barbarum and L. chinense has been reported ${ }^{17,18}$.

Due to significance of fruits of this plant in medicinal use, the work in this area has already been done. The aim of the present investigation is to report some of the new findings in the form of natural products from the fruits of $L$. chinense. In continuation of our study on Lycium fruits of L. chinense constituents, we have reported new and known compounds ${ }^{19,20}$. This paper describes the isolation and characterization of one new compound $\alpha$-D-glucopyranosyl- $\left(2 \rightarrow 1^{\prime}\right)-\alpha$-L-arabinopyranosyl-(2' $\rightarrow 1$ ")- $\alpha$-L-arabinopyranosyl-(2" $\rightarrow 1$ "')- $\alpha$-Larabinopyranoside (1) (Fig. 1) from the fruits of L. chinense.

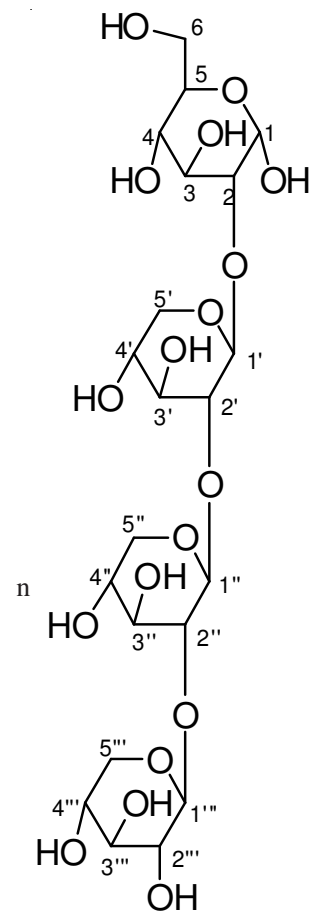

Fig. 1. Chemical structure of compound 1 


\section{EXPERIMENTAL}

Optical rotation was measured with an instrument on an AA-10 model polarimeter (Instruments Ltd, Seoul, South Korea). IR spectra were recorded on a Infinity Gold FT-IR (Thermo Mattson, USA) spectrophotometer, which was available at Korea Institute of Science and Technology, Seoul, South Korea. Both ${ }^{1} \mathrm{H}$ and ${ }^{13} \mathrm{C}$ NMR spectra were obtained on a Bruker Avance 600 high resolution spectrometer operating at 600 and $150 \mathrm{MHz}$, respectively. This NMR machine was available at Seoul National University (SNU), Seoul, South Korea and all NMR spectra were recorded at Seoul National University (Instrument, Bruker, Germany). NMR spectra were obtained in deuterated methanol and chloroform using tetramethylsilane (TMS) as an internal standard, with chemical shifts expressed in ppm $(\delta)$ and coupling constants $(J)$ in Hz. FAB/MS data were recorded on a JMS-700 (Jeol, Japan) spectrometer instrument which was available at SNU, Seoul, South Korea. All chemicals used were of analytical grade. Hexane, ethyl acetate, chloroform, methanol, ethanol, water, sulphuric acid and vanillin were purchased from Daejung Chemicals and Metals Co. Ltd, Korea. Pre-coated thin layer chromatography (TLC) plates (layer thickness $0.25 \mathrm{~mm}$ ), silica gel for column chromatography (70-230 mesh ASTM) and LiChroprep RP-18 (40$63 \mu \mathrm{m})$ were from Merck (Darmstadt, Germany).

Fruits of Lycium chinense were purchased from local medicinal plants shop market in Seoul, Korea and were identified by the Head, Department of Pharmacognosy. Voucher specimen No. KU/LC/2010 has been deposited in Department of Applied Life Science, Konkuk University.

The fruits of $L$. chinense $(3.1 \mathrm{~kg}$ ) were immersed in methanol $(8 \mathrm{~L})$ for three days at room temperature and then the supernatant was concentrated under vacuum to yield $230 \mathrm{~g}$ of the extract, which was suspended in water and extracted with hexane, ethyl acetate and $n$-butanol successively to produce $20 \mathrm{~g}, 10.1 \mathrm{~g}$ and $40 \mathrm{~g}$ extract respectively.

The entire butanol extract was subjected to normal phase column chromatography over silica gel $(600 \mathrm{~g})$ to yield 28 fractions (each of $500 \mathrm{~mL}$ ) with the following eluants: fractions 1-2 with $\mathrm{CHCl}_{3}$, fractions 3-4 with $\mathrm{CHCl}_{3}-\mathrm{MeOH}$ (9.5:0.5), fractions 5-6 with $\mathrm{CHCl}_{3}-\mathrm{MeOH}$ (9:1), fractions 7-8 with $\mathrm{CHCl}_{3}-\mathrm{MeOH}(8: 2)$, fractions 9-10 with $\mathrm{CHCl}_{3}-\mathrm{MeOH}$ (7:3), fractions 11-12 with $\mathrm{CHCl}_{3}-\mathrm{MeOH}(6: 4)$, fractions 13-14 with $\mathrm{CHCl}_{3}-\mathrm{MeOH}(1: 1$,$) , fractions 15-16$ with $\mathrm{CHCl}_{3}-\mathrm{MeOH}$ (4:6), fractions 17-18 with $\mathrm{CHCl}_{3}-\mathrm{MeOH}$ (3:7), fractions 19-20 with $\mathrm{CHCl}_{3}-\mathrm{MeOH}$ (2:8), fractions 21-22 with $\mathrm{CHCl}_{3}-\mathrm{MeOH}$ (1:9) and fractions 23-28 with $\mathrm{MeOH}$. All fractions were examined by TLC. Fractions 1-4 were not further separated due to the low amount of the substance. Fractions 9-10 (4.4 g) were re-chromatographed over LiChroprep RP-18 (ODS silica gel; 40-63 $\mu \mathrm{m}$ : $200 \mathrm{~g}$; each fraction $100 \mathrm{~mL}$ ). The elution was sequentially performed with methanol and water to yield 20 fractions ( $50 \mathrm{~mL}$ each): fractions $1-4$ with $\mathrm{H}_{2} \mathrm{O}-\mathrm{MeOH}$ (8:2), fractions 5-8 with $\mathrm{H}_{2} \mathrm{O}-\mathrm{MeOH}(6: 4)$, fractions 9-12 with $\mathrm{H}_{2} \mathrm{O}-\mathrm{MeOH}$ (4:6), fractions $13-16$ with $\mathrm{H}_{2} \mathrm{O}-\mathrm{MeOH}(2: 8)$, 17-20 with methanol. Fractions 9-12 were re-chromatographed over Lichroprep RP18 ODS (80 g, each fraction of $50 \mathrm{~mL}$ ). The elution was sequentially performed with methanol containing $80,60,40,20,10$ and $0 \%$ of water to yield two new compounds previously ${ }^{19}$ and one new compound $(\mathbf{1}, 32$ $\mathrm{mg})$.

$\alpha$-D-glucopyranosyl-( $\left.2 \rightarrow 1^{\prime}\right)-\alpha$-L-arabinopyranosyl$\left(2^{\prime} \rightarrow 1^{\prime \prime}\right)-\alpha$-L-arabinopyranosyl-(2' $\left.\rightarrow \mathbf{1}^{\prime \prime \prime}\right)-\boldsymbol{\alpha}$-L-arabinopyranoside (1): Colourless semi solid; $\mathrm{R}_{\mathrm{f}} 0.33\left(\mathrm{CHCl}_{3}: \mathrm{MeOH}\right.$; $7: 3) ;[\alpha]_{\mathrm{D}}{ }^{22}+45.1(c, 1) ;{ }^{1} \mathrm{H}(600 \mathrm{MHz})$ and ${ }^{13} \mathrm{C}$ NMR $(150$ MHz) (Table-1); IR (KBr, $\left.\nu_{\max }, \mathrm{cm}^{-1}\right)$; 3510, 3460, 3367, 3281, 2934, 2855, 1641, 1410, 1055, 818 ; FAB MS (positive mode) $m / z, 577[\mathrm{M}+\mathrm{H}]^{+}\left(\mathrm{C}_{21} \mathrm{H}_{36} \mathrm{O}_{18}\right)(10.8), 443$ (13.7), 311 (14, 179 (19.3), 163 (100).

TABLE-1

${ }^{1} \mathrm{H}$ AND ${ }^{13} \mathrm{C}$ NMR SPECTRAL DATA OF COMPOUND (1) ${ }^{\mathrm{a}}$

\begin{tabular}{clc}
\hline Position & \multicolumn{1}{c}{${ }^{1} \mathrm{H} \mathrm{NMR}$} & ${ }^{13} \mathrm{C} \mathrm{NMR}$ \\
\hline 1 & $5.13 \mathrm{~d}(6.1)$ & 99.26 \\
2 & $4.01 \mathrm{dd}(11.4,6.1)$ & 84.06 \\
3 & $3.86 \mathrm{~m}$ & 73.77 \\
4 & $3.74 \mathrm{~m}$ & 65.86 \\
5 & $4.07 \mathrm{~m}$ & 77.90 \\
6 & $3.30 \mathrm{brs}$ & 60.59 \\
$1^{\prime}$ & $4.17 \mathrm{~d}(6.6)$ & 105.85 \\
$2^{\prime}$ & $3.78 \mathrm{dd}(6.6,3.0)$ & 83.09 \\
$3^{\prime}$ & $3.73 \mathrm{~m}$ & 72.77 \\
4 & $3.70 \mathrm{~m}$ & 72.19 \\
$5^{\prime}$ & $3.49 \mathrm{br} \mathrm{s}$ & 62.63 \\
$1^{\prime \prime}$ & $5.23 \mathrm{~d}(4.2)$ & 103.14 \\
$2^{\prime \prime}$ & $3.96 \mathrm{dd}(4.2,9.6)$ & 77.46 \\
$3^{\prime \prime}$ & $3.55 \mathrm{~m}$ & 71.78 \\
$4^{\prime \prime}$ & $3.71 \mathrm{~m}$ & 69.38 \\
$5^{\prime \prime}$ & $3.33 \mathrm{br} \mathrm{s}$ & 64.56 \\
$1^{\prime \prime \prime}$ & $5.88 \mathrm{~d}(6.6)$ & 99.33 \\
$2^{\prime \prime \prime}$ & $3.43 \mathrm{dd}(5.4,6.6)$ & 76.65 \\
$3^{\prime \prime \prime}$ & $3.62 \mathrm{~m}$ & 71.16 \\
$4^{\prime \prime \prime}$ & $3.76 \mathrm{~m}$ & 65.05 \\
$5^{\prime \prime \prime}$ & $3.65 \mathrm{br} \mathrm{s}$ & 64.17 \\
\hline
\end{tabular}

${ }^{a}$ Coupling constant in $\mathrm{Hz}$ are provided in parenthesis

\section{RESULTS AND DISCUSSION}

Compound $\mathbf{1}$, a tetraglycoside was obtained from methanol extract. It responded to glycosidal test positively and IR absorption bands for hydroxyl groups at 3510, 3460, 3367 and $3281 \mathrm{~cm}^{-1}$. On the basis of FAB mass and ${ }^{13} \mathrm{C}$ NMR spectra, the molecular weight of $\mathbf{1}$ has been determined at $\mathrm{m} / \mathrm{z} 576$ consistent to the molecular formula of tetraglycoside $\mathrm{C}_{21} \mathrm{H}_{36} \mathrm{O}_{18}$. The ion fragments arising at $m / z, 163\left[\mathrm{C}_{6} \mathrm{H}_{11} \mathrm{O}_{5}\right]^{+}, 179$ $\left[\mathrm{C}_{6} \mathrm{H}_{11} \mathrm{O}_{6}\right]^{+}, 311\left[\mathrm{C}_{6} \mathrm{H}_{11} \mathrm{O}_{6}-\mathrm{C}_{5} \mathrm{H}_{8} \mathrm{O}_{4}\right]^{+}, 443\left[\mathrm{C}_{6} \mathrm{H}_{11} \mathrm{O}_{6}-\mathrm{C}_{5} \mathrm{H}_{8} \mathrm{O}_{4}-\right.$ $\left.\mathrm{C}_{5} \mathrm{H}_{8} \mathrm{O}_{4}\right]^{+}$and $149\left[\mathrm{C}_{5} \mathrm{H}_{9} \mathrm{O}_{5}\right]^{+}$suggested that the molecule possessed three units of pentose sugar linked to a hexose sugar in the terminal position (Fig. 2).

The ${ }^{1} \mathrm{H}$ NMR spectrum of $\mathbf{1}$ showed four one-proton doublets at $\delta 5.13(J=6.1 \mathrm{hz}), 4.17(J=6.6), 5.23(J=4.2 \mathrm{~Hz})$ and $5.88(J=6.6 \mathrm{~Hz})$ assigned to $\alpha$-oriented H-1, H-1', H-1" and $\mathrm{H}-1$ "' anomeric protons respectively. Four two-protons broad signals at $\delta 3.30,3.49,3.33$ and 3.65 were ascribed to oxygenated methylene $\mathrm{H}_{2}-6, \mathrm{H}_{2}-5$ ', $\mathrm{H}_{2}-5$ " and $\mathrm{H}_{2}-5$ "' protons, respectively. The other sugar protons resonated from $\delta 4.07$ to 3.43 . The absence of signals only from $\delta 5.23$ to 3.30 suggested glycosidic nature of the molecule. The ${ }^{13} \mathrm{C}$ NMR spectrum of 1 displayed signals for anomeric carbons at 99.26 (C-1), 105.85 (C-1'), 103.14 (C-1") and 99.33 (C-1"'), oxygenated 


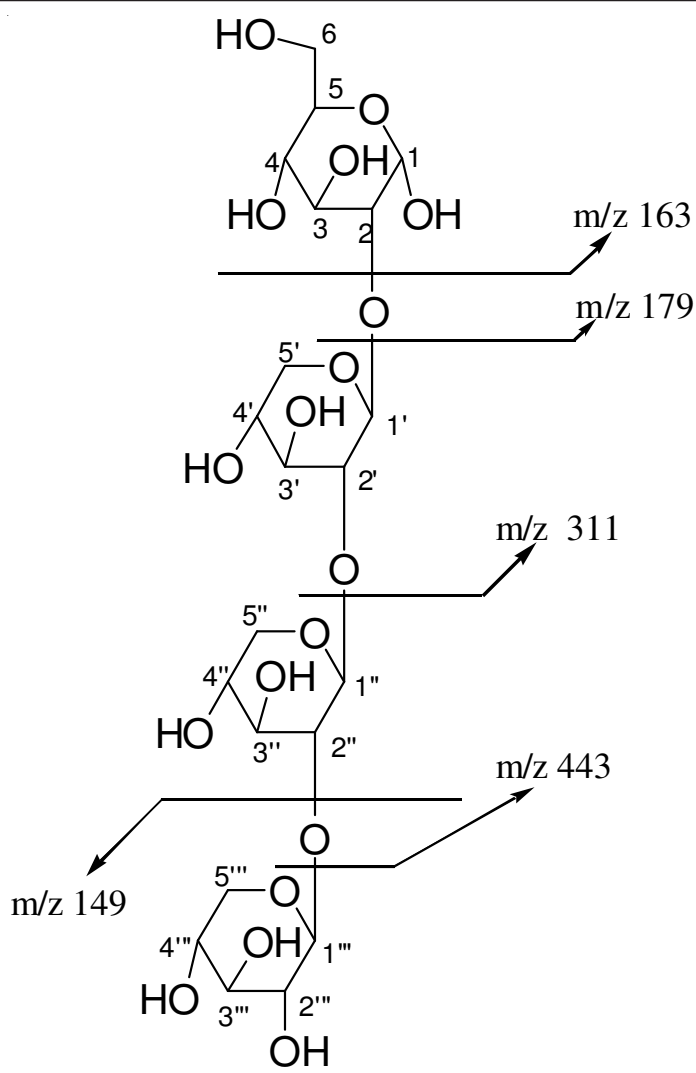

Fig. 2. Fragmentation patterns of compound $\mathbf{1}$

methylene carbons at $\delta 60.59$ (C-6), 62.63 (C-5'), 64.56 (C$5 ")$ and 64.17 (C-5"'), other sugar carbons from $\delta 84.06$ to 65.05 .

The ${ }^{1} \mathrm{H}-{ }^{1} \mathrm{H}$ COSY spectrum of $\mathbf{1}$ showed correlations of H-1 with $\mathrm{H}-2, \mathrm{H}-3$ and $\mathrm{H}-5$; $\mathrm{H}-2$ with $\mathrm{H}-3, \mathrm{H}-4$ and $\mathrm{H}-1$ '; H-2' with $\mathrm{H}-1$ ', H-3' and H-1"; and H-1"'and H-2" with H-1", H-3" H-1"'. The HMBC spectrum of 1 exhibited that C-2 interacted with H-1, H-3, H-4 and H-1'; C-1" interacted with H-2', H-2" and $\mathrm{H}-3$ "' and C-1"' interacted with H-2", H-2"', H2-5"' and H$3 " '$. The HSQC spectrum of $\mathbf{1}$ showed important correlations of $\mathrm{H}-1$ at $\delta 5.13$ with $\mathrm{C}-1$ at $\delta 99.26, \mathrm{H}-2$ at $\delta 4.01$ with $\mathrm{C}-2$ at $\delta 84.06, \mathrm{H}-1^{\prime}$ at $\delta 4.17$ with $\mathrm{C}-1^{\prime}$ at $\delta 105.85, \mathrm{H}_{2}-5^{\prime}$ at $\delta 3.49$ with $\mathrm{C}-5^{\prime}$ at $\delta 62.63, \mathrm{H}-1^{\prime \prime}$ at $\delta 5.23$ with $\mathrm{C}-1^{\prime \prime}$ at $\delta 103.14$ and
H-1"' at $\delta 5.88$ with C-1"' at $\delta 99.33$. The presence of C-2 at $\delta$ $84.06, \mathrm{C}-2$ ' at $\delta 83.09$ and C-2" at $\delta 77.46$ in the deshielded region suggested $(2 \rightarrow 1)$ linkages of the sugar units. Acid hydrolysis of 1 yielded glucose and arabinose. On the basis of spectral data analysis and chemical reactions, the structure of 1 has been established as $\alpha$-D-glucopyranosyl- $\left(2 \rightarrow 1^{\prime}\right)-\alpha-\mathrm{L}-$ arabinopyranosyl-(2' $\rightarrow 1$ ")- $\alpha$-L-arabinopyranosyl-(2" $\rightarrow 1$ "')- $\alpha$ L-arabinopyranoside. This a new tetracyclic glycoside.

\section{REFERENCES}

1. Y. Peng, C. Ma, Y. Li, K.S.Y. Leung, Z.H. Jiang and Z. Zhao, Plant Foods Hum. Nutr., 60, 161 (2005).

2. Pharmacopoeia of the People's Republic of China, Chemical Industry Press: Beijing (2000).

3. S. Funayama, K. Yoshida, C. Konno and H. Hikino, Tetrahedron Lett., 21, 1355 (1980).

4. J. Yamahara, M. Kim, T. Sawada and H. Fujimua, Shoyakugaku Zasshi, 18, 33 (1964).

5. S.Y. Kim, Y. Choi, H. Huh, J. Kim, Y.C. Kim and H.S. Lee, J. Nat. Prod., 60, 274 (1997).

6. M. Noguchi, K. Mochida, M. Shingu, K. Kozuka and K. Fujitani, Chem. Pharm. Bull. (Tokyo), 32, 3584 (1984).

7. K. Jung, Y.W. Chin, Y.W. Kim and Y.C. Kim, J. Arch. Pharm. Res, 28, 1381 (2005).

8. Y.G. Shin, K.H. Cho, J.H. Kim, M.K. Park and J.H. Park, J. Chromatogr. A, 857, 331 (1999).

9. D.G. Lee, H.J. Jung and E.R. Woo, Arch. Pharm. Res., 28, 1031 (2005).

10. N. Asano, A. Kato, M. Miyauchi, H. Kizu, T. Tomimori, K. Matsui, R.J. Nash and R.J. Molyneux, Eur. J. Biochem., 248, 296 (1997).

11. Z. Zhang, X. Liu, T. Wu, J. Liu, X. Zhang, X. Yang, M.J. Goodheart, J.F. Engelhardt and Y. Wang, Cell Biol. Toxicol., 27, 107 (2011).

12. C.C. Wang, S.C. Chang, B.S. Inbaraj and B.H. Chen, Food Chem., 120, 184 (2010).

13. Y.-W. Chin, S.W. Lim, S.-H. Kim, D.-Y. Shin, Y.-G. Suh, Y.-B. Kim, Y.C. Kim and J. Kim, Bioorg. Med. Chem. Lett., 13, 79 (2003).

14. S. Yahara, C. Shigeyama, T. Ura, K. Wakamatsu, T. Yasuhara and T. Nohara, Chem. Pharm. Bull. (Tokyo), 41, 703 (1993).

15. X. Peng and G. Tian, Carbohydr. Res., 331, 95 (2001).

16. Q. Zheng, Z.Y. Zheng, X. Xu and Z.H. Hu, Biochem. Syst. Ecol., 38, 275 (2010).

17. X.M. Li, X.L. Li and A.G. Zhou, Eur. Polym. J., 43, 488 (2007).

18. M. Ming, L. Guanhua, Y. Zhanhai, C. Guang and Z. Xuan, Food Chem., 113, 872 (2009).

19. I.M. Chung, M. Ali, E.H. Kim and A. Ahmad, J. Asian Nat. Prod. Res., 15, 136 (2013)

20. J.H. Lee, I.M. Chung, J.D. Lim, N.A. Siddiqui and A. Ahmad, Asian J. Chem., 25, 4664 (2013). 